\title{
A first formal approach to animal spirits beyond uncertainty
}

Gerasimos T. Soldatos, American University of Athens

Erotokritos Varelas, University of Macedonia

\begin{abstract}
Standard Macroeconomics treats animal spirits as a source of uncertainty disturbing otherwise rational expectations. But, Keynesian animal spirits ensue from suboptimal emotional responses to socioeconomic status change beyond matters of uncertainty. This paper identifies such spirits with the disturbance from the optimal decision-making implied by an emotional well-being utility function. The introduction of a policy-maker, holding its own view of private welfare in a society of emotional individuals, generates by itself, i.e. in the absence of animal spirits, uniform business fluctuations. This is the result of the income redistribution needed to reconcile the policy-maker's with the emotional individual's view of private welfare. Consequently, if animal-spirits induced fluctuations are already present when a policy-maker is introduced in the economy, the aim of policy intervention should be the design of that income redistribution that would not aggravate the business cycle but that would end up in uniform only cycles, with the aid perhaps of discretionary interest rate policy. Nevertheless, if animal spirits do not exist when the policy-maker enters the system, the income-redistribution induced cycles may incite such spirits by themselves in which case the cycles will not be of the uniform type. All comes down to "income and emotion", to an ageless and ecumenical fact of life, complicated purposefully or not by authority.
\end{abstract}

\section{JEL Classification}

D63; E32; E43; H11; Z13.

\section{Keywords}

Animal spirits; Emotions; Socio-economic status; Individual vs. social perception of private welfare; Business cycles.

\section{Acknowledgement}

We are grateful to two anonymous reviewers for useful comments and suggestions. 


\section{Introduction}

'Most, probably, of our decisions to do something positive, the full consequences of which will be drawn out over many days to come, can only be taken as the result of animal spirits - a spontaneous urge to action rather than inaction, and not as the outcome of a weighted average of quantitative benefits multiplied by quantitative probabilities': This is precisely what Keynes $(1936,162)$ had said about animal spirits in his General Theory. Since then macroeconomics tried successfully to distance the field from the notion of animal spirits, because they are not susceptible to data and reason (or control by government); uncertainty and risk came to replace it - rightly from one point of view as we shall soon see rationalizing concepts such as business confidence accordingly (Roskam 2014). Indeed, many, like Frantz (2005) and Shiller (2015) see in animal spirits sheer irrationality. But, the truth of the matter is that Keynes himself did not identify animal spirits with uncertainty contrary to what mainstream macroeconomics maintains. Akerlof and Shiller's (2009) widely appreciated book on the subject points to the possibility of 'predictable irrationality'. And, others, like Pech and Milan (2009) and Schwartz (2010) try to appreciate animal spirits in the light of cognitive psychology towards some behavioural macroeconomics. It is this last approach to the matter, which is promising, simply because irrationality is not predictable and much more rationalizable by definition. The matter is really one of rationalizing emotions.

According to Pham (2007) and Cohen et al. (2007), for example, emotions arise from a cognitive appraisal of the emotional object or situation in terms of its meaning for one's well-being: This is the case with the so-called "integral emotional responses", otherwise emotion states are defined to be "incidental" ones. And, according to Scherer (2011), for instance, three conceptions of rationality need to be distinguished in discussing the relation between emotion and rationality. The first is rational in the sense of intellectual/inferential, emphasizing reasoning, consistency, and logic à la Kahneman (1994). The second is rational in the sense of functional/purposeful, pertaining to the optimality of the means-end relationship à la Aristotle's notion of practical reason (Nicomachean Ethics, Ross 1908) or Weber's (1964) Zweckrationalität. And the third type of rationality is rational in the sense of reasonable/consensual, associated with behaviours and actions that are "rational" not because they are logically consistent or serve one's self-interest but because they fulfill broader societal goals, comply with superior moral values, or back greater evolutionary purposes even against one's material self-interest, much à la Weber's (1964) Wertrationalität, (Clore 2005).

These definitions of emotion types and rationality types in connection with emotion are standard in the relevant literature. Could it be that the strict separation between ratio and passio, maintained by mainstream economics, derives methodologically from Plato's notion of a tripartite soul that categorically distinguishes between cognition, emotion and motivational urges (Republic IV, Jowett 1892)? The answer is negative, because Plato, the inventor of the notion of 'rationality' (Moss 2008), also points out that virtue is a matter of 'harmonizing the three [parts of soul], just like the three notes in a musical scale, lowest and highest and middle' (Republic IV, 443d, Jowett 1892). So, not only realism but also methodology dictates the incorporation of emotion to economic theory towards the investigation of the influence of animal spirits on microeconomic behaviour and macroeconomic performance. It is straightforward logically to associate incidental emotion states with uncertainty and risk, which need not bother us here because it has already received much attention by the literature.

Therefore, a first approximation to the notion of animal spirits is what the present paper tries to offer by confining analytically attention to integral emotional responses in connection with functional rationality. Animal spirits may be emanating from other rationality types and from incidental emotion states with 
implications far more complex than "simple" uncertainty. But, outside the scope of uncertainty, the emotion-rationality nexus studied here is the simplest one analytically, because a utility function may be employed and because there does exist in the literature Parada-Daza and Parada-Contzen's (2013) utility function incorporating emotional well-being. The next section offers a formal definition of animal spirits based on a version of this utility function. It is followed by a section clarifying this definition from a macroeconomic point of view in a Kaldor-type environment. The paper concludes with still another section pointing to the complexity of a holistic approach to animal spirits, encompassing not only integral emotional responses but incidental emotion states too, the latter in the form of uncertainty. Such an approach becomes much more effortful when one attempts to incorporate in the analysis consensual rationality and inferential rationality; the former in the form, for instance, of Staveren's (2007) ethics in economics, and the latter by considering explicitly framing effects and the like.

\section{The Formal Definition of Animal Spirits}

To model the genuinely Keynesian notion of animal spirits, the one which is dissociated from uncertainty, their presence is introduced into an otherwise certain environment. Following Parada-Daza and Parada-Contzen (2013), the version of individual emotional utility function considered here is:

$$
U(h, f)=\operatorname{alog}(1+h Y)+b \sin (2 \pi f Y \cdot h Y)
$$

where $a$, and $b$, are constants, with $a+b=1$, showing the proportion utility derives from pure rationality and emotion, respectively, under the particular historical period being experienced by the individual in its lifetime. $f \in(0,1)$ captures emotion regulation by constantly adjusting the emotional response either itself qualitatively (fine-tuning) or its intensity (volume adjustment) given the intent of the emotion. Alternatively, in terms of Kahneman and Deaton's $(2010,16489)$ distinction between emotional well-being ('the frequency and intensity of experiences of joy, stress, sadness, anger, and affection that make one's life pleasant or unpleasant') and life evaluation ('thoughts that people have about their life when they think about it'), $b$ and $f$ might be connected with life evaluation and emotional well-being, respectively. And, $h \in(0,1)$ is the share of individual income, $y$, to total steady-state income, $Y$, and is a choice variable too, from the point of view of how much one wants to work to increase one's share to total income: $h=q \zeta L^{1 / \eta} / Y$, where $L$ is labor, $q$ is the wage rate, $\zeta$ is some positive coefficient, and the constant $\eta \geq 1$. The focus is on $h$ rather than on $L$, because it hinges upon the broader matter of income distribution, which is of concern herein.

Emotions are exogenous to the economy and give rise to instability once $f$ is not the one matching $h$ :

$$
\frac{\partial U}{\partial f}=0 \Rightarrow f= \pm \frac{1}{4} h
$$

That is, there is an optimal feedback loop between the dynamic unfolding of emotion and the evolution of socio-economic status, which once ruptured, animal spirits and instability will crop out. Put differently, it is one thing to react emotionally when it is required (emotion elicitation), another to react with the appropriate emotion (emotion differentiation). One reason, for instance, why (2) may be violated is cognitive biases like those of prospect theory. Animal spirits and the subsequent instability are the outcome of inappropriate emotional response; inappropriate from the viewpoint of disturbing (2). Figure $1 \mathrm{~A}$, with $h$ on the horizontal axis and $U(h, f)$ on the vertical, illustrates this utility function under $a=0.6$, and $b=0.4$. The blue line assumes that $f=0.2$ while the red line is based on stronger emotions described by a value of $f=0.6$. The destabilizing influence of $f$ is clear once (2) is violated; much more so when emotion is strong $(f=$ 
0.6 vs. $f=0.2$ ) and national income is higher as is the case with the left-hand of the figure where $Y=2$ whereas in the right-hand part, $Y=1$. Now, animal spirits are defined to be the outcome of the violation of (2), with subsequent destabilizing influence as depicted by Figure $1 \mathrm{~A}$. Increased income share is not always consonant with increased utility unless emotion adjusts as indicated by (2), leaving the area below the blue or red line, leaving that is, welfare unchanged.

Ideally, lines such as these, $U$ lines, should be parallel to the horizontal axis, but $f$ may lag behind $h$, welfare may not be stable over the lifetime, and what really matters is that instability does not influence total welfare once the individual passes away: The areas above and below the parallel $U$ line cancel each other out. Yet, comparing areas below blue and red lines in Figure 1A, emotions cause a big loss in welfare in the right-hand part, which is not the case in the left-hand part with the lower $Y$. So, animal spirits do take their toll on welfare, and welfare instability may be attributed to the effort of the individual to deal with the welfare changes coming out of the violation of (2). Much more so when one considers emotion to be the main source of utility as the comparison between the black lines ( $a=0.4, b=0.6)$ and the violet lines $(a=0.6, b=0.4)$ in Figure 1B illustrates under $Y=1$. This awareness of the individual regarding the role of emotion, prompting action and reaction on its part, is what prevents a characterization of it as irrational. There does exist rationality, which although it may not be the emotion-free, $f=0 \Rightarrow$ $\sin (2 \pi f Y \cdot h Y)=0$, is nevertheless some sort of emotional rationality. As such, it tries to solve the optimization problem:

$$
\max _{h, f} \mathcal{U}=\operatorname{alog}(1+h Y)+b \sin (2 \pi f Y \cdot h Y)+\theta(y-h Y)
$$

Figure $1 \mathrm{~A}$
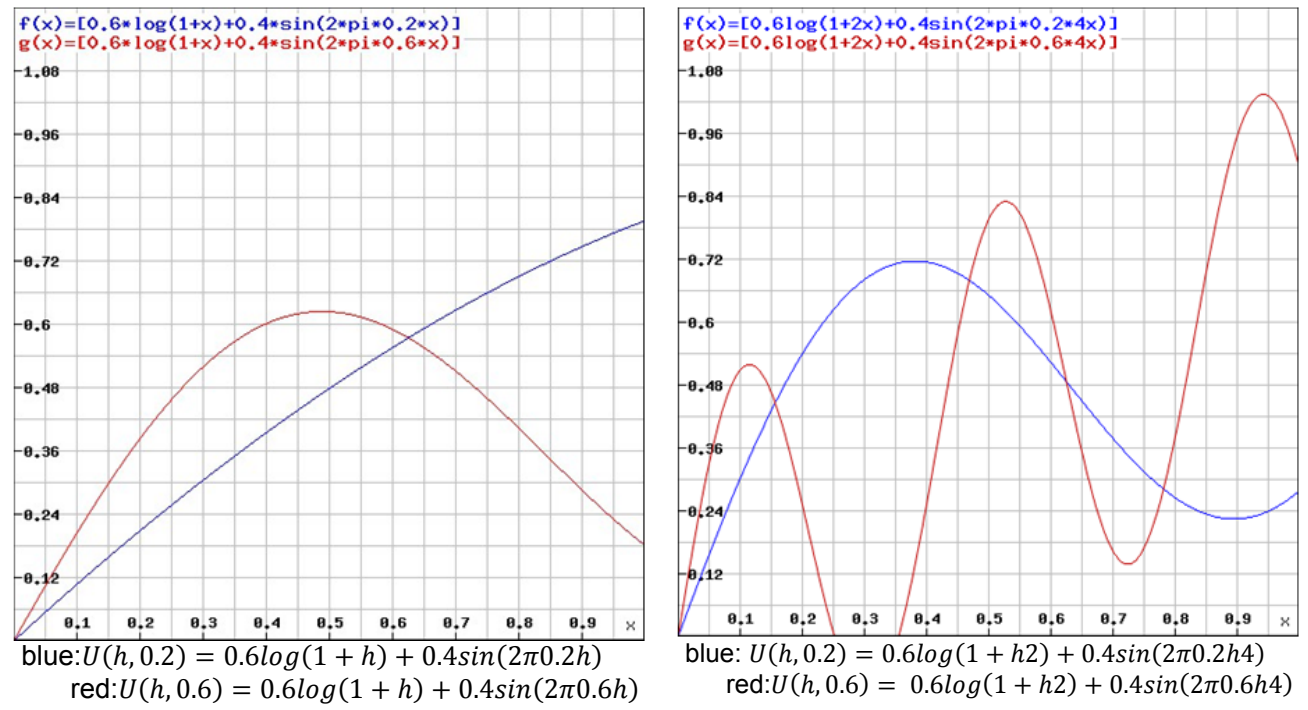
Figure 1B

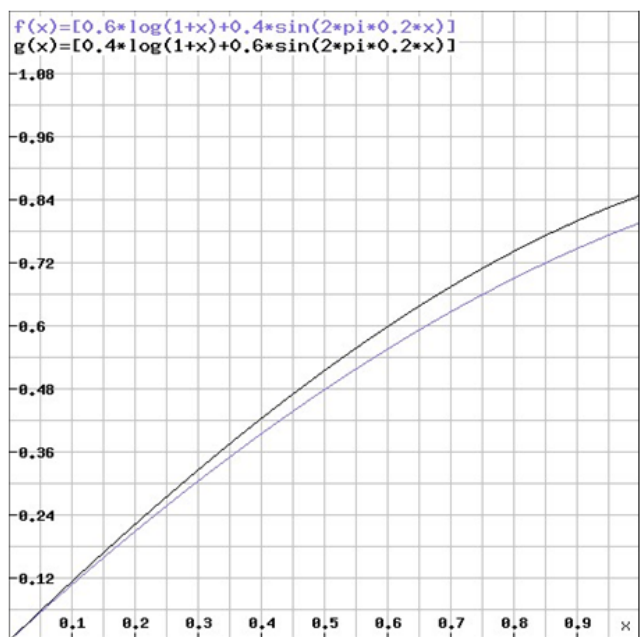

velvet: $U(h, 0.2)=0.6 \log (1+h)+0.4 \sin (2 \pi 0.2 h)$ black: $U(h, 0.2)=0.4 \log (1+h)+0.6 \sin (2 \pi 0.2 h)$

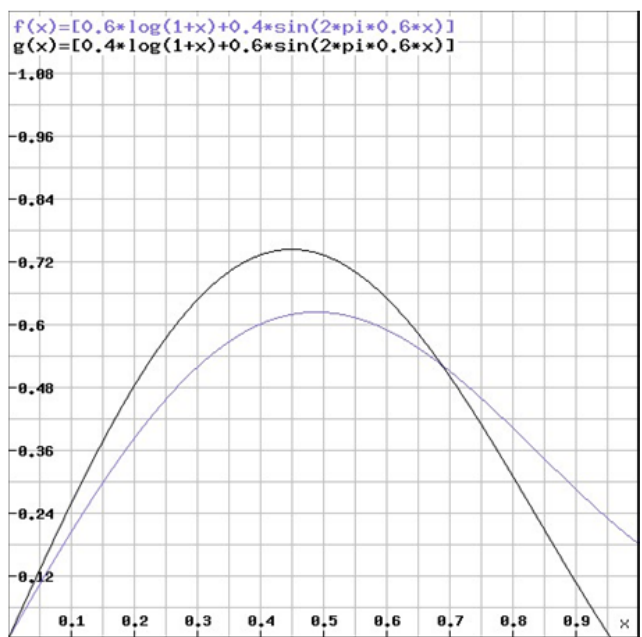

velvet: $U(h, 0.6)=0.6 \log (1+h)+0.4 \sin (2 \pi 0.6 h)$ black: $U(h, 0.6)=0.4 \log (1+h)+0.6 \sin (2 \pi 0.6 h)$

where: $y=h Y$ is the income constraint. The emotional rationalization first-order conditions include (2) and:

$$
\frac{\partial U}{\partial h}=2 b \pi f Y \cdot \cos (2 \pi f Y \cdot h Y) Y+\frac{a Y}{1+h Y}-\theta Y=0
$$

or, in short:

$$
\theta Y=\frac{\partial U}{\partial h}
$$

$\theta$ is the marginal utility of individual income. The marginal private welfare from individual income given by the first two terms (and divided by $Y$ ), has to be equated with this marginal utility. That is, emotion may be inducing private welfare fluctuations over the life span, but once it is rationalized in the sense of endeavouring to minimize unpleasant outcomes out of (2)'s disturbance, $\left(3^{\prime}\right)$ will come to characterize the individual over the lifetime. According to this condition, a person who is emotionally rational too, thinks that if for some reason (2) were violated, it would be optimal on its part if the temporary welfare ups and downs had counterbalanced each other in the end of its life, having been locked up by $\theta Y$. Such a result is in line with the hypotheses regarding the self-fulfilling socioeconomic-status beliefs in the long-run (Piketty 1998).

Nevertheless, we have seen that once (2) is disturbed, $\left(3^{\prime}\right)$ is unlikely to be satisfied as well: Animal spirits have consequences, which the policy-maker has to address. Suppose that the incumbent has a world view reflected through the following Bergson-Samuelson social welfare function:

$$
\begin{gathered}
W=\sum \beta^{m} U^{m} \\
W=\sum \beta^{m}[\operatorname{alog}(1+h Y)+b \sin (2 \pi f Y \cdot h Y)]^{m}
\end{gathered}
$$

where the $\beta$ 's are weights attached to individual $U$ 's so that $\Sigma \beta=1$, and the summation operator, $\sum$, applies to the entire population. Figure 1 depicts the way the policy-maker views individual utility when $m=1=\beta$. Figures 2 and 3 show this under $m=0.5$ and $m=1.5$, respectively, continuing for comparison but also simplicity purposes to assume that $\beta=1$. These diagrams verify the comments made on the basis of Figure 1, and suggest in addition the three of them that the increase in $m$ amplifies utility volatility. $m$ (and $\beta$ ) reflect policy-maker's perception of society, which clearly has a powerful effect on the course of the economy. In this paper, it is the ineffective policy-maker who allows exogenous emotion to become 
endogenous to the economy, provoking ultra-emotional spirits that reinforce instability. The reaction of citizenry in response to erroneous policy-making is labelled ultra-emotional because adds to pre-existent exogenous emotion.

Figure 2

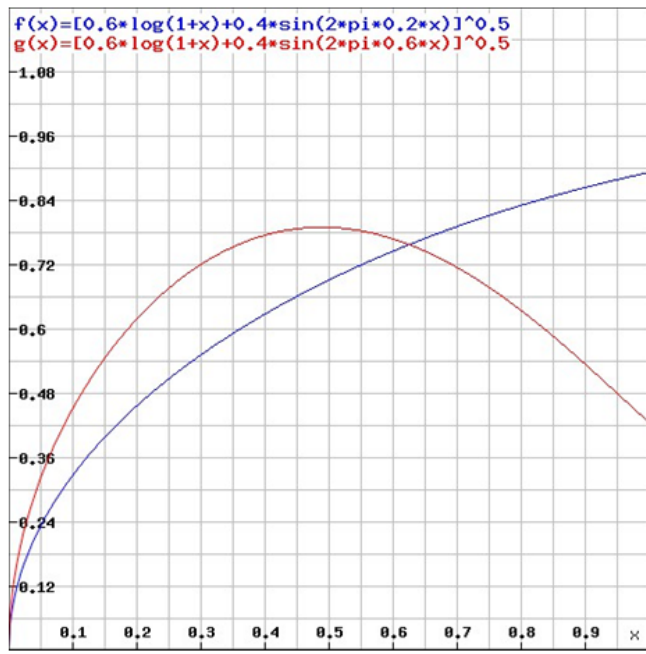

blue: $U(h, 0.2)=\sqrt{0.6 \log (1+h)+0.4 \sin (2 \pi 0.2 h)}$

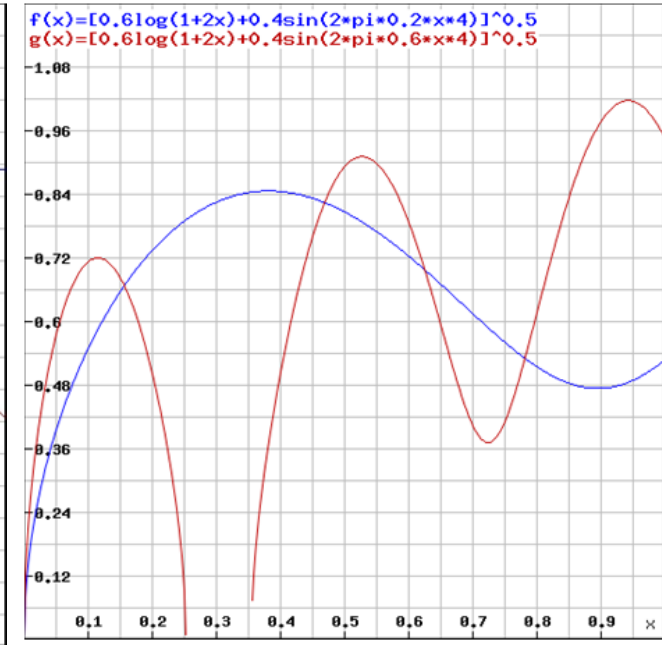

red: $U(h, 0.6)=\sqrt{0.6 \log (1+h)+0.4 \sin (2 \pi 0.6 h)}$

blue: $U(h, 0.2)=\sqrt{0.6 \log (1+h 2)+0.4 \sin (2 \pi 0.2 h 4)}$

red: $U(h, 0.6)=\sqrt{0.6 \log (1+h 2)+0.4 \sin (2 \pi 0.6 h 4)}$

Figure 3
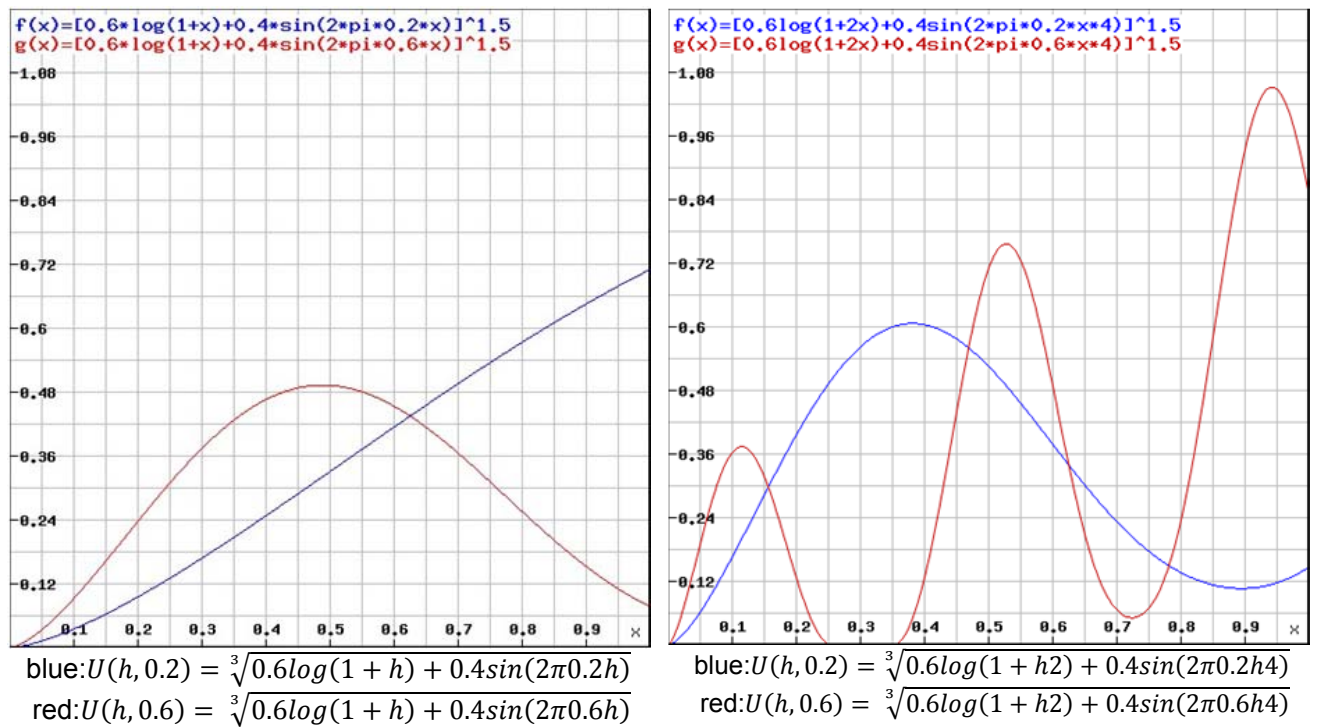

Now, the policy-maker's optimization problem is:

$$
\max _{h, Y} \mathcal{W}=\sum \beta^{m}[\operatorname{alog}(1+h Y)+b \sin (2 \pi f Y \cdot h Y)]^{m}+\vartheta\left(Y-\sum h Y\right)
$$

where: $Y=\sum h Y$ is the relevant income constraint. That is, authorities are interested not only in income distribution, i.e. in manipulating $h$ so that the average, so to speak, $f$ is matched, but also in keeping $Y$ at its steady state. The first-order conditions are:

$$
\begin{gathered}
\frac{\partial \mathcal{W}}{\partial h}=m \beta^{m}[2 b \pi f Y \cdot \cos (2 \pi f Y \cdot h Y) Y \\
\left.+\frac{a Y}{1+h Y}\right][\operatorname{alog}(1+h Y)+b \sin (2 \pi f Y \cdot h Y)]^{m-1}-\vartheta Y=0
\end{gathered}
$$

or: 


$$
\frac{\partial \mathcal{W}}{\partial h}=m \beta^{m} \frac{\partial U}{\partial h} U^{m-1}-\vartheta Y=0
$$

and

$$
\frac{\partial \mathcal{W}}{\partial Y}=\sum m \beta^{m} \frac{\partial U}{\partial h} \frac{h}{Y} U^{m-1}+\vartheta\left(1-\sum h\right)=0 \underset{(4)}{\Rightarrow} \vartheta \sum h=0 \Rightarrow \vartheta=0
$$

$\vartheta$ is the marginal utility of national income to the policy-maker. Being equal to zero to satisfy (5), it would in turn imply from (4) that $\partial U / \partial h=0$ and hence, from ( $\left.3^{\prime}\right)$ that $\theta=0$, which indeed might be the case at a steady state of universal bliss. But, once such an eventuality is unrealistic, (5) explains that this can be so because

$$
1-\sum h \neq 0 \Rightarrow 1-\sum q \zeta L^{1 / \eta} / Y \neq 0 \Rightarrow Y-\sum q \zeta L^{1 / \eta} \neq 0
$$

that is because more or less than $Y$ is expected by the policy-maker to be distributed among the individuals, and expectations are frustrated. So, although individuals would be content if (2) and $\left(3^{\prime}\right)$ were satisfied, the policy-maker will be pleased only if what it considers to be universal bliss $(\vartheta=\theta=0=\partial U / \partial h)$ is attained. There is clearly a public-private sector discrepancy in the valuation of individual welfare even if there were no animal spirits: From (3) and (4), $\vartheta=$ $\theta m \beta^{m} U^{m-1}$; the two theta are not the same. And, the residual income implied by (6) goes, as we shall see shortly in the next section, as rate of return to physical capital.

Steady-state general equilibrium requires the conversion of (6) into equality:

$$
Y=\sum q \zeta L^{1 / \eta}
$$

in which case, $h=q \zeta L^{1 / \eta} / Y=q \zeta L^{1 / \eta} / \sum q \zeta L^{1 / \eta}$. According to the policy-maker this is the condition describing prudent policy-making when (2) and $\left(3^{\prime}\right)$ are violated, or the same, in the presence of animal spirits. Improper is the policy-making when the marginal private welfare from individual income differs from the marginal social welfare of the same income as seen by the policy-maker. But, we just saw that the presence and only of a policy-maker causes such a discrepancy even if all in the economy runs smoothly. This discrepancy, engendering loss of confidence and trust towards the policy-maker, is the source of emotions, of ultra-emotional spirits, destabilizing the economy (a) by itself in the form of uniform cycles as we shall see below, if (2) and (3) are satisfied, (b) even further than exogenous emotion does if (2) and (3) are violated. If $m>1$, condition $\left(6^{\prime}\right)$ is necessary but not sufficient to prevent the emergence of ultra-emotional spirits as may be seen through the following, for example, second-order derivative:

$$
\begin{aligned}
& \frac{\partial^{2} \mathcal{W}}{\partial h^{2}}=-m \beta^{m}\left[4 b \pi f^{2} Y^{2} \cdot \sin (2 \pi f Y \cdot h Y) Y^{2}+\frac{a Y^{2}}{(1+h Y)^{2}}\right] U^{m-1} \\
& +m(m-1) \beta^{m}\left(\frac{\partial U}{\partial h}\right)^{2} U^{m-2}<0
\end{aligned}
$$

This derivative is always negative if $m \leq 1$ in which case, condition $\left(6^{\prime}\right)$ is both necessary and sufficient to ensure absence of animal spirits. But, if $m>1$, the second derivative will be negative only if its positive term is absolutely smaller than its negative one. In this case, additional conditions beyond the satisfaction of $\left(6^{\prime}\right)$ are needed to have a negative cross-partial and prevent the appearance of animal spirits when (2) is breached.

\section{The Macroeconomics Perspective of Animal Spirits}

Additional insight into the meaning of (6) and $\left(6^{\prime}\right)$ may be gained by considering it from a macroeconomic point of view à la Dana and Malgrange (1993) as follows. Emotion frequency, $f$, changes with time according to some function, and any disturbance of $\left(6^{\prime}\right)$ and change thereby in $f$ implies disequilibrium in the goods market and discrepancy between investment, 


$$
I=v \frac{d Y}{d f}
$$

and saving,

$$
S=s Y
$$

altering $Y$ according to

$$
\frac{d Y}{d f}=e(I-S)
$$

or inserting (7) and (8) in (9),

$$
\frac{d Y}{d f}=e(I-S)=\frac{e s Y}{e v-1}
$$

where: $v$ is the accelerator, $s$ is the propensity to save, $e$ is the speed of adjustment of supply to demand, and the derivative with respect to $f$, is used in the place of the time derivative entering customarily dynamic analysis.

In view of,

$$
I-S=\mu\left(Y-\sum q \zeta L^{1 / \eta}\right)
$$

(10) may be rewritten as follows,

$$
\frac{d Y}{d f}=e(I-S)=e \mu\left(Y-\sum q \zeta L^{1 / \eta}\right)
$$

which in turn implies that

$$
s=\mu\left(Y-\sum q \zeta L^{1 / \eta}\right)(e v-1)
$$

That is, in view of $\left(6^{\prime}\right)$, at steady-state general equilibrium, $s=0$, which prompts another perspective of what prudent policy-making means as follows: One might have sensed from the diagrams above that the area below the blue lines tends to be greater than that under the red lines, suggesting a higher welfare level for the less emotional individuals given the presence of animal spirits. Proper policymaking according to the policy-maker means income redistribution aiming at compensating for welfare differences owing to differences in animal-spirits related emotion, ceteris paribus; policy-making should be neutralizing "exogenous", nonpolicy induced animal spirits if it does not want to become part of the problem. This is very important, because it tends to take care of the destabilizing influence caused by the introduction and only of a policy-maker in the economy, too. Animal spirits come up and have critical consequences for the stability of output once policy does not accomplish this task.

One can see this through what stability means under $s=0$, by noting that outside the stead-state, conditions (3) and (4) imply that $\vartheta=\theta m \beta^{m} U^{m-1} \Rightarrow$

$$
\begin{gathered}
\theta m \beta^{m}\left[\operatorname{alog}(1+h Y)+b \sin \left(2 \pi f h Y^{2}\right)\right]^{m-1}=\vartheta \Rightarrow \\
\sin \left(2 \pi f h Y^{2}\right)=\frac{1}{b}\left(\frac{\vartheta}{\theta m \beta^{m}}\right)^{\frac{1}{m-1}}-\frac{\operatorname{alog}(1+h Y)}{b}
\end{gathered}
$$

which means that $s=0$ along a uniform cycle unless $f=0$, in which case:

$$
\log (1+h Y)=\frac{1}{a}\left(\frac{\vartheta}{\theta m \beta^{m}}\right)^{\frac{1}{m-1}} \Rightarrow Y=\left\{\exp \left[\frac{1}{a}\left(\frac{\vartheta}{\theta m \beta^{m}}\right)^{\frac{1}{m-1}}\right]-1\right\} / h
$$

Stability in the form of uniform cycles is what macroeconomic stability and steadystate mean for the policy-maker when society consists of emotional individuals. If there are no animal spirits, such cycles are the result of the income redistribution 
pursued by the policy-maker to reconcile the social (its own) view of private welfare with the individual's view of its own welfare. And, uniform oscillations are consequently what the policy-maker would have in mind as the goal of its intervention to subdue animal spirits when they do exist. If they do not exist, the income-redistribution induced cycles may trigger animal spirits by themselves in which case they will not be of the uniform type.

The course of physical capital, $K$, would be shaped by these developments if

$$
I=K \frac{d K}{d f}
$$

which is a Kaldor-like assumption, and which in view of (7) gives:

$$
\frac{d K}{d f}=\frac{v}{K} \frac{d Y}{d f}
$$

The path of $K$ is a scaled down version of that of $Y$. So, once condition (2) is violated for some reason, and is not plausible to expect to be restored through ( $\left.6^{\prime}\right)$, what becomes important as second best policy-making is to ensure that

$$
\frac{d Y}{d f} \frac{1}{Y}=\rho_{Y}=e \mu\left(\vartheta-\theta m \beta^{m} U^{m-1}\right)>0
$$

i.e. that the cycles are prevented from obtaining a downward trend, as prescribed by the relationship:

$$
\rho_{Y} \lesseqgtr 0 \text { iff } \vartheta \lesseqgtr \theta m \beta^{m} U^{m-1}
$$

Income redistribution is one policy means towards that direction, but the rate of interest, $r$, can become a second one, because, letting $i^{2}=-1$,

$$
\sin \left(2 \pi f h Y^{2}\right)=\frac{e^{2 \pi i f h Y^{2}}-e^{-2 \pi i f h Y^{2}}}{2 i}=\frac{e^{f h Y^{2}}-e^{-f h Y^{2}}}{2 i}
$$

and, circumventing the matter of cycles, one can postulate that $1+r=e^{-h Y^{2}} \Rightarrow$ $Y=[h \log (1+r)]^{-1 / 2}$ so that

$$
\frac{d Y}{d r}=-\frac{1}{2(1+r)[h \log (1+r)]^{3 / 2}}
$$

as Figure 4 shows in the $r-Y$ space for $h=0.1, h=0.01$, and $h=0.001$. Hence,

$$
\sin \left(2 \pi f h Y^{2}\right)=\frac{(1+r)^{-f}-(1+r)^{f}}{2 i}
$$

obtaining in turn from (12):

$$
Y=\left\{\exp \left[\frac{1}{a}\left(\frac{\vartheta}{\theta m \beta^{m}}\right)^{\frac{1}{m-1}}-\frac{b(1+r)^{-f}-b(1+r)^{f}}{2 a i}\right]-1\right\} / h
$$

The cross-partial derivative $\partial^{2} Y / \partial f \partial r$ in the Appendix is negative, capturing the important role interest rate policy can play in influencing animal spirits. 
Figure 4

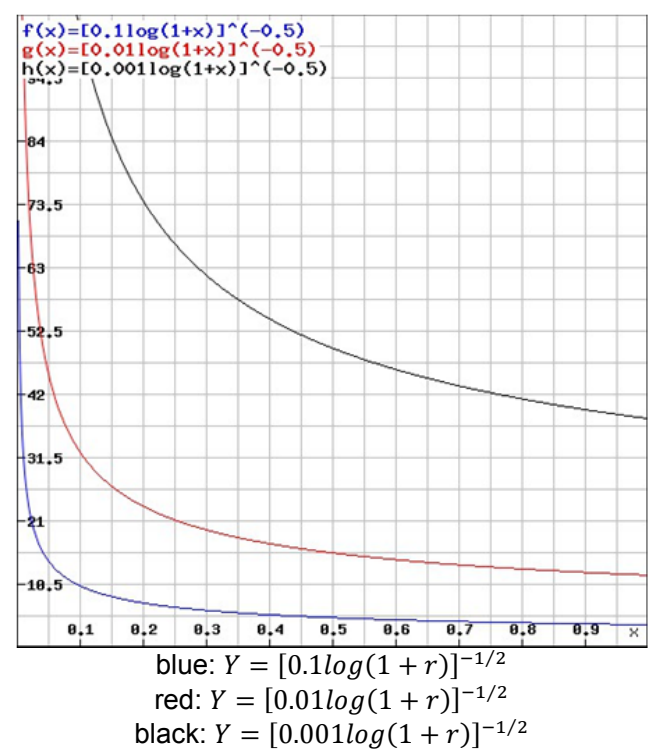

The intuitive reason is pretty clear: In the presence of animal spirits, capital markets are inefficient, the loanable funds doctrine simply does not hold, and there can be no natural rate of interest (Pilkington 2014). Yet, note that the relevant policy prescription is not exactly Moore's (1988) 'horizontalism' that the central bank set a certain rate of interest as a policy target and then let the quantity of money float. This would be the case if the matter of cycles was assumed away as is the case behind Figure 4; an assumption made for algebraic tractableness. But, animal spirits are synonymous to fluctuations, and interest rate policy should be discretionary, taking on a flavour of "verticalist" interest rate float. As Arestis (2011) points out, a Taylor rule presumes the existence of a natural rate of interest à la Wicksell (2007 [1898]), which is not the case here unless a fluctuating natural rate is somehow contemplated... What is for sure is that: '...the short-term output responses are more sensitive to animal spirits in the fixed interest rate regime than in the variable one. Thus the interest rate response under the variable interest rate regime tend to reduce the impact of animal spirits on the transmission mechanism, thereby reducing the volatility in this transmission' (De Grauwe 2012, 53). Moreover, the animal spirits in this paper are first and foremost exogenous, unrelated to economic uncertainty, which only the ineffective policy-maker can trigger and add to the exogenous emotion. The viewpoint about a liquidity preference as a buffer against economic uncertainties should be appreciated accordingly.

\section{Concluding Remarks}

To sum up: Animal spirits ensue from suboptimal lifetime integral emotional response to socioeconomic status change under functional rationality. The introduction of a policy-maker, holding its own view of private welfare in a society of emotional individuals, generates by itself, i.e. in the absence of animal spirits, uniform business fluctuations. This is the result of the income redistribution needed to reconcile the policy-maker's with the emotional individual's view of private welfare. Consequently, stability restoration in the presence of animal spirits involves policy-making to restore the uniform character of cycles through income redistribution and perhaps discretionary interest rate policy. Nevertheless, if animal spirits do not exist, the income-redistribution induced cycles may incite such spirits by themselves in which case the cycles will not be of the uniform type.

The situation becomes much more perplexed when the uncertainty originating in incidental emotional states is added to this picture. Incidental states may be taking, 
for example, the form of a random disturbance term, $\epsilon$, with mean, $\bar{\epsilon}$, and variance, $\sigma_{\epsilon}^{2}$, in an environment in which $a$ is uncertain too, with mean, $\bar{a}$, and variance, $\sigma_{a}^{2}$. Under such circumstances, one has to choose $f$ and $h$ so as to keep $U$ as close to $\epsilon=0$ on average as possible:

$$
\begin{aligned}
\min E[\epsilon] \equiv & E\left\{\left[\operatorname{alog}(1+h Y)+(1-a) \sin \left(2 \pi f h Y^{2}\right)-0\right]^{2}\right\}= \\
\sigma_{\epsilon}^{2}+[\bar{a} \log (1+ & \left.h Y)+(1-\bar{a}) \sin \left(2 \pi f h Y^{2}\right)\right]^{2}+\sigma_{a}^{2}[\bar{a} \log (1+h Y) \\
& \left.+(1-\bar{a}) \sin \left(2 \pi f h Y^{2}\right)\right]^{2} \\
& +2 c \sigma_{a} \sigma_{\epsilon}\left[\bar{a} \log (1+h Y)+(1-\bar{a}) \sin \left(2 \pi f h Y^{2}\right)\right]
\end{aligned}
$$

where $E$ is the expectations operator and $c$ is the correlation coefficient between $a$ and $\epsilon$. It is clear that introducing the simplest holistic approach to animal spirits in economics complicates the discipline considerably, and this may be one reason of confining attention only to the implications from uncertainty. Much more so when such an approach should also be encompassing not so much the explicit treatment inferential rationality's cognitive biases that invalidate (2) as the matter of consensual rationality à la say Staveren's (2007) ethics.

The simplest way to incorporate ethics in (1) is to add a term indicating how the rest of society affects the individual, with the positive/negative sign if the influence is positive or negative:

$$
\begin{aligned}
U(h, f)=\operatorname{alog}(1+h Y)+b \sin \left(2 \pi f h Y^{2}\right) & \\
& \pm(1-a-b)\{\gamma \log [1+(1-h) Y]+\delta \sin [2 \pi f Y(1-h) Y]\}
\end{aligned}
$$

The bracketed term after the " \pm " sign reflects society's utility function, which is independent of how the individual feels: $\gamma+\delta=1$; society does not care about a given individual. The first-order conditions are now:

$$
\frac{\partial U}{\partial f}=2 \pi\left\{b h Y^{2} \cos \left(2 \pi f h Y^{2}\right) \pm(1-a-b) \delta(1-h) Y^{2} \cos \left[2 \pi f(1-h) Y^{2}\right]\right\}=0
$$

and

$$
\begin{gathered}
\frac{\partial U}{\partial h}=2 \pi b f Y^{2} \cos \left(2 \pi f h Y^{2}\right)+\frac{a Y}{1+h Y} \mp \frac{(1-a-b) \gamma Y}{1+(1-h) Y} \\
\mp 2 \pi(1-a-b) \delta Y^{2} \cos \left[2 \pi f(1-h) Y^{2}\right]=0
\end{gathered}
$$

It is clear that the coordination between integral emotional response and socioeconomic status change becomes much more difficult than under (2). The same difficulty characterizes individual effort to even out the temporary welfare ups and downs over the lifetime vis-à-vis what ( $\left.3^{\prime}\right)$ dictates. And, of course, even more likely becomes the destabilizing "capacity" of the policy-maker.

Now, this scenario behind (15) has to be merged with the one behind (14) to have a truly holistic approach to animal spirits. What such an intricate venture will produce in practice is certainly increased alertness in policy-making, improved finetuning. Of course, a piece of the story will always be missing in the real world, but fine-tuning minimizes the fears that something which is theoretically wrong has been done, that the theoretical background of policy intervention was not a sound one, in the sense of falsifying observations. In this connection, it is methodologically improper to identify animal spirits with an exogenous random shock of a stationary rational-expectations equilibrium (Howitt 1992) because the source of the shock may be anything, and a result like 'Bayesian updating induces convergence to the equilibrium with positive probability even if people start with no definite belief that animal spirits affect the profitability of hiring' (Howitt 1992, 493) may be quite misleading in so far as policy-making is concerned. The same holds at least policy-wise when animal spirits are tried to be approached empirically as 'interrelations between waves of optimism and pessimism' (Chauvet and Guo 2003,140 ) because any such approach is subject to Lucas critique. 
In any case, the profession does already know that when crises break up, a piece of the story is missing because of animal spirits beyond those associated with uncertainty. So, the least the profession can start doing about it from now on, analytically, of course, and in so far as it purports to be empirically relevant, is to cease confusing "nature" with smoothness. Akerlof and Shiller (2009) report a great many reasons attesting to this call; and cognitive psychology, "twice" as many: All come down to "income and emotion", to an ageless and ecumenical fact of life, complicated purposefully or not by authority... It is this fact of life that made Keynes $(1923,80)$ emphasise that the: '...long run is a misleading guide to current affairs. In the long run we are all dead. Economists set themselves too easy, too useless a task, if in tempestuous seasons they can only tell us, that when the storm is long past, the ocean is flat again.' Indeed, 'psychological ideas... are more important in Keynes's economic theory than is sometimes recognized' (Barnett $2015,307)$, which perfectly justifies his support for discretionary policy-making as this paper does, too. Does a version of Okun's law $\left(10^{\prime}\right)$ not favour active employment policy-making beyond discretionary monetary policy?

\section{Appendix}

Let $R=(1+r)$ and $\Theta=\vartheta^{-(m-1)} / a\left(\theta m \beta^{m}\right)^{-(m-1)}$. From (13),

$$
\frac{\partial Y}{\partial f}=-\frac{i b \log R\left(1+R^{2 f}\right) \exp \left[-\frac{i b R^{2 f}-2 a \Theta R^{f}-i b}{2 a R^{f}}\right]}{2 a h R^{f}}
$$

and consequently,

$$
\frac{\partial^{2} Y}{\partial f \partial r}=-\frac{\exp \left[-\frac{i b R^{2 f}-2 a \Theta R^{f}-i b}{2 a R^{f}}\right] \Lambda}{4 a^{2} h b R^{1+2 f}}
$$

where $\Lambda=f\left[b R^{4 f}+2 i a R^{3 f}+2 b R^{2 f}-2 i a R^{f}+b\right] \log R+2 i a R^{3 f}+2 i a R^{f}$

\section{References}

Akerlof, George A. and Robert J. Shiller (2009) Animal Spirits: How Human Psychology Drives the Economy, and Why it Matters for Global Capitalism. Princeton, NJ: Princeton University Press.

Arestis, Philip (2011) 'Keynesian Economics and the New Consensus in Macroeconomics', in E. Hein and E. Stockhammer (eds) A Modern Guide to Keynesian Macroeconomics and Economic Policies, 88-111. Cheltenham, UK: Elgar.

Barnett, Vinvent (2015) 'Keynes and the Psychology of Economic Behavior: From Stout and Sully to The General Theory', History of Political Economy 47(2): 307333.

Chauvet, Marcelle and Jang-Ting Guo (2003) 'Sunspots, Animal Spirits, and Economic Fluctuations', Macroeconomic Dynamics 7(1): 140-169.

Clore, Gerald L. (2005) 'For Love or Money: Some Emotional Foundations of Rationality', Chicago Kent Law Review 80(3): 1151-1165.

Cohen, Joel B., Michel Tuan Pham, and Eduardo B. Andrade (2007) 'The Nature and Role of Affect in Consumer Judgment and Decision Making', in C. P. Haugtvedt, P. M. Herr, and F. R. Kardes (eds) Handbook of Consumer Psychology, 297-438. Mahwah, NJ: Erlbaum.

Dana, Rose-Anne and Pierre Malgrange (1993) 'The Dynamics of a Discrete Version of a Growth Cycle Model', in M. Jarsulic (ed) Non-Linear Dynamics in Economic Theory, 497-524: Aldershot: Elgar. 
De Grauwe, Paul (2012) Lectures on Behavioral Macroeconomics. Princeton, NJ: Princeton University Press.

Frantz, Roger S. (2005) Two Minds: Intuition and Analysis in the History of Economic Thought. New York: Springer.

Howitt, Peter (1992) 'Animal Spirits', American Economic Review 82(3): 493-507.

Jowett, Benjamin (trans. and ed) (1892) 'Republic', in The Dialogues of Plato, vol. 3. Oxford: Oxford University Press: http://classics.mit.edu/Plato/republic.html

Kahneman, Daniel (1994) 'New Challenges to the Rationality Assumption', Journal of Institutional and Theoretical Economics - Zeitschrift Fur Die Gesamte Staatswissenschaft 150(1): 18-36.

Kahneman, Daniel and Angus Deaton (2010) 'High Income Improves Evaluation of Life but not Emotional Well-being', Proceedings of the National Academy of the USA 107(38): 16489-16493: http://www.pnas.org/content/107/38/16489.long

Keynes, John Maynard (1923) A Tract on Monetary Reform. London: Macmillan.

Keynes, John Maynard (1936) The General Theory of Employment, Interest and Money. London: Macmillan.

Kraut, Richard (2014) 'Aristotle's Ethics', in E.N. Zalta (ed) The Stanford Encyclopedia of Philosophy, (Summer 2014 Edition): http://plato.stanford.edu/archives/sum2014/entries/aristotle-ethics/>.

Moore, Basil J. (1988) Horizontalists and Verticalists: The Macroeconomics of Credit Money. Cambridge, MA: Cambridge University Press.

Moss, Jessica (2008) 'Appearances and Calculations: Plato's Division of the Soul', Oxford Studies in Ancient Philosophy 34: 35-68.

Parada-Daza, Jose Rigoberto and Miguel Ignacio Parada-Contzen (2013) 'Economic and Emotional Rationality: An Application to Wealth Concentration', Theoretical Economics Letters 3(4): 233-244.

Pech, Wesley and Marcelo Milan (2009) 'Behavioral Economics and the Economics of Keynes', Journal of Socio-Economics 38(6): 891-902.

Pham, Michel Tuan (2007) 'Emotion and Rationality: A Critical Review and Interpretation of Empirical Evidence', Review of General Psychology 11(2): 155178.

Piketty, Thomas (1998) 'Self-fulfilling Beliefs about Social Status', Journal of Public Economics 70: 115-132.

Pilkington, Philip (2014) 'Endogenous Money and the Natural Rate of Interest: The Reemergence of Liquidity Preference and Animal Spirits in the Post-Keynesian Theory of Capital Markets', Levy Economics Institute Working Paper No. 817: http://www.levyinstitute.org/pubs/wp_817.pdf

Roskam, John (2014) 'Interest Rate Tweaks Won't Manufacture Animal Spirits', Financial Review Oct 10, 2014: http://www.afr.com/news/economy/monetarypolicy/interest-rate-tweaks-wont-manufacture-animal-spirits-20141009-11cnpf

Ross, William David (trans. and ed) (1908) Nicomachean Ethics. Oxford: Clarendon Press: http://classics.mit.edu/Aristotle/nicomachaen.html

Scherer, Klaus R. (2011) 'On the Rationality of Emotions: or, When are Emotions Rational?', Social Science Information 50(3-4): 330-350.

Schwartz, Hugh (2010) 'Does Akerlof and Shiller's Animal Spirits Provide a Helpful New Approach for Macroeconomics?', Journal of Socio-Economics 39(2): 150-154. 
Shiller, Robert J. (2015) Irrational Exuberance, 3rd ed. Princeton, NJ: Princeton University Press.

Staveren, Irene Van (2007) 'Beyond Utilitarianism and Deontology: Ethics in Economics', Review of Political Economy 19(1): 21-35.

Weber, Max (1964) 'Wirtschaft und Gesellschaft', in J. Winckelmann (ed) Grundriss der verstehenden Soziologie. Cologne: Kiepenheuer \& Witsch.

Wicksell, Knut (2007 [1898]) Interest and Prices: A Study of the Causes Regulating the Value of Money. Digitally by Mises Institute: https://mises.org/library/interestand-prices. 